\title{
CHARACTERISATION OF AmCCR1 AND pseudoCOMTAm PROMOTERS IN Acacia mangium
}

\author{
AZMAH ABDUL LATIF ${ }^{1}$, SHEH MAY TAM ${ }^{2}$ and WICKNESWARI RATNAM ${ }^{1 *}$ \\ ${ }^{1}$ School of Environmental and Natural Resource Sciences, Faculty of Science and Technology, \\ Universiti Kebangsaan Malaysia, 43650 Bangi Selangor, Malaysia \\ ${ }^{2}$ School of Biosciences, Taylor's University \\ "E-mail:wicki@ukm.edu.my
}

Accepted 13 June 2020, Published online 30 June 2020

\begin{abstract}
Acacia mangium is one of the most important species in forest plantation industry in Southeast Asia. Lignin is a complex polymer found in plant which has to be removed using harsh and toxic chemicals for the production of high quality paper. Understanding the complex pathway that underlies the regulation of lignin biosynthetic genes requires in depth knowledge of the genes involved and it's regulatory elements. Using Thermal Asymmetric Interlaced PCR, a 770bp promoter of pseudoCOMTAm and 619bp of AmCCRl promoter were isolated. Bioinformatics analysis revealed the presence of cis acting elements commonly found in lignin biosynthetic genes such as TATA box, CAAT box, W box, AC-I and AC-11 elements on both promoters.
\end{abstract}

Key words: Acacia mangium, AmCCR1 promoter, pseudoCOMTAm promoter, sequence analysis

\section{INTRODUCTION}

Lignin is a complex aromatic polymer mainly found in plant secondary cell wall (Boerjan et al., 2003) which plays an important role in plant development (Jones et al., 2001) and defence mechanism (Lauvergeat et al., 2001). Being the second most abundant biopolymer after cellulose, it is a major challenge to the paper and pulp industry because of the recalcitrance to efficient pulp production (Whetten et al., 1998). Plants with reduced lignin content or altered lignin composition are desirable for the industry. Because of its economic importance, tremendous effort has been put since few decades to uncover the lignin biosynthetic pathway which has been proved to be highly complex (Grima-Pettenati \& Goffner, 1999; Boudet et al., 2003) and the genes involved have multiple cross talk with other physiological process (Zhao \& Dixon, 2011).

Lignin polymer consists of three different monomers, which are p-hydroxyphenyl $(\mathrm{H})$, guaiacyl (G) and syringyl (S) units. Angiosperm's lignin consists of mainly $\mathrm{G}$ and $\mathrm{S}$ subunit. Caffeic

* To whom correspondence should be addressed. acid O-methyltransferase (COMT) and CinnamoylCoA reductase (CCR) are two enzymes involved in $\mathrm{G}$ and $\mathrm{S}$ units production (Shi et al., 2010). Similar to other genes involved in lignin biosynthesis pathway, $C C R$ and $C O M T$ exist as gene family in many plant species. However, only one $C C R$ and one COMT gene was shown to have high expression in xylem tissues and is predicted to have major function in lignification during development (Raes et al., 2003; Shi et al., 2010).

Acacia mangium, an important forest tree species has an estimated worldwide plantation of 1.4 M ha (Griffin et al., 2011). It is planted widely in South East Asia and used mainly for the production of pulp and paper (Griffin et al., 2011). Transcriptome sequencing on A. mangium found important genes involved in the lignin biosynthetic pathway (Wong et al., 2011). A comparative study of small interfering RNA in high lignin and low lignin plants of $A$. mangium found some conserved as well as novel microRNAs which are predicted to have some important functions in lignin and secondary cell wall biosynthesis (Ong \& Wickneswari, 2011). The regulatory elements like promoter structures, transcription factors and miRNAs are important aspects to be taken into 
account; while studying the complex regulatory network of lignin biosynthesis.

In this study, promoter of AmCCR 1 and a new promoter of a pseudogene with high sequence similarity with COMT were isolated and characterised in silico. Both promoters are shown to have cis acting elements commonly found in lignin biosynthetic genes. Transcription factor binding site modelling shows presence of binding site for some important MYB transcription factors involved in lignin and secondary cell wall biosynthesis regulation on both promoters.

\section{MATERIALS AND METHODS}

\section{Plant Materials, Genomic DNA Isolation}

Young leave samples of $A$. mangium were obtained from Acacia plot W at Plant Biotechnology Laboratory, UKM, Malaysia. Genomic DNA was extracted using QIAGEN DNeasy Plant Mini Kit (Qiagen, Germany).

\section{Gene Isolation}

Isolation of both AmCCR1 and pseudoCOMTAm promoters were done using TAIL-PCR.

\section{Primer design for $A m C C R 1$}

Primers were designed based on contigAmCCRI sequence (Wong et al., 2011). CCR1, CCR2 and CCR3 primers together with arbitrary degenerate primer (AD6) were used to amplify the promoter region using TAIL-PCR. CCRE1ME4M F and CCRE1ME4M R primers were used to amplify exon 1 until exon 4 using normal PCR. Full sequence of exon 1 was amplified using CCRE1 F and CCR E1 R. CCRE4 F1 and CCRE4 F2 together with AD6 was used to amplify exon 4 and intron 4 using TAILPCR. CCRI4 F and CCR14 R were used to amplify full sequence of intron 4 and exon 5 (Table 1). Melting points $(\mathrm{Tm})$ for the designed gene specific primers were higher than $62^{\circ} \mathrm{C}$ as calculated with the formula of Mazars et al. (1991).

\section{Primer design for pseudoCOMTAm}

Two gene specific primers (GSP1 and GSP2) as designed by Sukganah et al. (2013) were used (Table 2). These primers were used as reverse primers, pairing with arbitrary degenerate (AD4) primer (Thanh et al., 2012) as forward primer. Based on the sequence of the first fragment, new primers were designed to further amplify the 5' and 3, regions (Table 2). GSP1, GSP2 and GSP3 were used

Table 1. Primer sequence for AmCCR1 isolation

\begin{tabular}{ll}
\hline Primer Name & Primer Sequence (5' to 3') \\
\hline CCR1 & CCGCGGTGGAGTGATCTCTCAGAAC \\
CCR2 & GGTGGATTGAAGCAATGGTCCCAG \\
CCR3 & GCCTCTCTCTAGGAGAAGTTGACAATCC \\
CCRE1ME4M F & GGATTGTCAAGCTTCTCCTAGAGAGAGGC \\
CCRE1ME4M R & CCGCGGTGGAGTGATCTCTCAGAAC \\
CCRE1 F & GAGGTGGGTAATTCTGGTAGGC \\
CCRE1 R & CCCAATTATGAATGGCTCTCATG \\
CCRE4 F1 & GGATTGTCAAGCTTCTCCTAGAGAGAGGC \\
CCRE4 F2 & GCAGCATGGGATGAGGCAAAAGC \\
AD 6 & AWGCANGNCWGANATA \\
CCRI4 F & GTTCTGAGAGATCACTCCACCGCGG \\
CCRI4 R & GTAGGGTTTTGCTCTTGG \\
\hline
\end{tabular}

Table 2. Primer utilized for isolation of pseudoCOMTAm

\begin{tabular}{ll}
\hline Primer Name & Primer Sequence (5' to $3^{\prime}$ ) \\
\hline GSP1 & CGAGGGCTGATTTGAGAATCATGGGAAG \\
GSP2 & TGGCTTCCTCGTCGTTGACATGGGTAGG \\
GSP3 & GTTTTTTAATTACCCCTATGCTACTCCAC \\
M1 & CCACACCCTTTTGCTGGAATCATCACC \\
M2 & GGTTCAGCCGGCGAGACTTAGATAACC \\
AD2 & NGTCGASWGANAWGAA \\
AD4 & AGWGNAGWANCAWAGG \\
\hline
\end{tabular}


in combination with AD2 to further amplify the 5' region. Primers M1, M2 and AD2 were used to further amplify the 3 ' region. Melting points $(\mathrm{Tm})$ for the designed gene specific primers was higher than $62^{\circ} \mathrm{C}$ as calculated with the formula of Mazars et al. (1991).

\section{TAIL-PCR Reaction}

TAIL-PCR was carried out as described by Liu \& Whittier (1995). The primary PCR reaction mixture consisted of $1 \mathrm{U}$ of HS Taq polymerase (Takara Bio Inc., Japan), 1× Taq polymerase buffer, $200 \mu \mathrm{M}$ dNTPs, $0.2 \mu \mathrm{M}$ RSP1 primer, $5 \mu \mathrm{M}$ of the AD primer, and $50 \mathrm{ng}$ of genomic DNA. The secondary PCR reaction consisted of $1 \times$ Taq polymerase buffer, $200 \mu \mathrm{M}$ dNTPs, $0.8 \mathrm{U}$ of HS Taq polymerase, $0.2 \mu \mathrm{M}$ RSP 2 primer, $4 \mu \mathrm{M}$ of the AD primer used in the primary reaction, and 50 fold dilution of the primary PCR product. The tertiary PCR mixture consisted of $1 \times$ Taq polymerase buffer supplied with the enzyme, $200 \mu \mathrm{M}$ dNTPs, $0.5 \mathrm{U}$ of HS Taq polymerase, $3 \mu \mathrm{M}$ of the AD primer used in the previous reactions, $0.3 \mu \mathrm{M}$ RSP3 primer, and 10 fold dilution of the secondary PCR product. The thermal cycling conditions are shown in Table 3. PCR products were visualized by electrophoresis on $1.0 \%(\mathrm{w} / \mathrm{v})$ agarose gels, purified using NucleoSpin Gel and PCR Clean-up kit and sequenced.

\section{Sequence Analysis}

Sequences were assembled and characterised using BioEdit (Hall 1999) and Clustal Omega (Sievers et al., 2011) before subjected to similarity search using BLASTn (Altschul et al., 1990). The promoter sequences were aligned to known COMT1 promoter sequence from Acacia auriculiformis $\times$ Acacia mangium hybrid, HQ317735.1 (Sukganah et al., 2013) and real CCR from Leucaena leucocephala (GU984572). Putative cis-acting elements were identified using PlantCARE (Lescot et al., 2002). The ORF of the gene was detected using ExPASy Translate Tool.

\section{RESULTS AND DISCUSSION}

\section{AmCCR1 Sequence Analysis}

Sequence analysis shows AmCCRl consists of $619 \mathrm{bp}$ of promoter (Genbank accession number: MK353215), 5 exons and 4 introns (Figure 1). Blast $\mathrm{N}$ analysis shows $A m C C R 1$ shares $88 \%$ similarity with Real CCR from Leucaena leucocephala (GU984572). However, Tail-PCR was unable to amplify full length of intron 4 and exon 5 .

Promoter of $A m C C R 1$ was shown to have multiple cis elements commonly present in promoters of lignin genes. TATA Box was found at -35 . Xylem specific elements, ACI and ACII were found at position +60 and +61 respectively. Real $C C R$ from Arabidopsis thaliana was also found to have ACI and ACII in it's promoter (Lauvergeat et al., 2001). 5UTR Py-rich stretch was found at position +44 . This element confers high transcriptional rate for the gene. TC rich repeats, an element involved in stress response and plant defence, was found at three positions in AmCCR1; $-195,-386$ and +15 . Box $\mathrm{S}$ which is also involved in plant defence was found at +153 . Some of these cis acting elements were also found in CCR from Leucaena leucocephala (Prashant et al., 2011).

\section{PseudoCOMTAm Sequence Analysis}

Using Thermal Asymmetric Interlaced PCR (TAIL-PCR), a combination of GSP1, GSP2 (Sukganah et al., 2013) and AD4 (Thanh et al., 2012) primers successfully amplified a $400 \mathrm{bp}$ fragment with $93 \%$ similarity with real COMT gene, AhgCOMT1 (HQ317735) from Acacia

Table 3. Thermal Cycling Conditions

\begin{tabular}{|c|c|c|}
\hline Reaction (primer combination) & Number of Cycles & Thermal cycling conditions \\
\hline Primary PCR & $\begin{array}{c}1 \\
5 \\
1 \\
15\end{array}$ & $\begin{array}{l}93^{\circ} \mathrm{C}, 1 \mathrm{~min} ; 95^{\circ} \mathrm{C}, 1 \mathrm{~min} \\
94^{\circ} \mathrm{C}, 30 \mathrm{~s} ; 62^{\circ} \mathrm{C}, 1 \mathrm{~min} ; 72^{\circ} \mathrm{C}, 2.5 \mathrm{~min} \\
94^{\circ} \mathrm{C}, 30 \mathrm{seC} ; 25^{\circ} \mathrm{C}, 3 \mathrm{~min} ;{ }^{\circ} 72^{\circ} \mathrm{C}, 2.5 \mathrm{~min} \\
94^{\circ} \mathrm{C}, 10 \mathrm{~s} ; 68^{\circ} \mathrm{C}, 1 \mathrm{~min} ; 72^{\circ} \mathrm{C}, 2.5 \mathrm{~min} \\
94^{\circ} \mathrm{C}, 10 \mathrm{~s} ; 68^{\circ} \mathrm{C}, 1 \mathrm{~min} ; 72^{\circ} \mathrm{C}, 2.5 \mathrm{~min} \\
94^{\circ} \mathrm{C}, 10 \mathrm{~s} ; 29^{\circ} \mathrm{C}, 1 \min ; 72^{\circ} \mathrm{C}, 2.5 \min \\
72^{\circ} \mathrm{C}, 5 \min \end{array}$ \\
\hline Secondary PCR & $\begin{array}{l}12 \\
1\end{array}$ & $\begin{array}{l}94^{\circ} \mathrm{C}, 10 \mathrm{~s} ; 64^{\circ} \mathrm{C}, 1 \mathrm{~min} ; 72^{\circ} \mathrm{C}, 2.5 \mathrm{~min} \\
94^{\circ} \mathrm{C}, 10 \mathrm{~s} ; 64^{\circ} \mathrm{C}, 1 \mathrm{~min} ; 72^{\circ} \mathrm{C}, 2.5 \mathrm{~min} \\
94^{\circ} \mathrm{C}, 10 \mathrm{~s} ; 29^{\circ} \mathrm{C}, 1 \mathrm{~min} ; 72^{\circ} \mathrm{C}, 2.5 \mathrm{~min} \\
72^{\circ} \mathrm{C}, 5 \mathrm{~min}\end{array}$ \\
\hline Tertiary PCR & $\begin{array}{c}20 \\
1\end{array}$ & $\begin{array}{l}94^{\circ} \mathrm{C}, 15 \mathrm{~s} ; 29^{\circ} \mathrm{C}, 30 \mathrm{~s} ; 72^{\circ} \mathrm{C}, 2 \mathrm{~min} \\
72^{\circ} \mathrm{C}, 5 \mathrm{~min}\end{array}$ \\
\hline
\end{tabular}

* ramping to $72^{\circ} \mathrm{C}$, over $3 \mathrm{~min}$ 


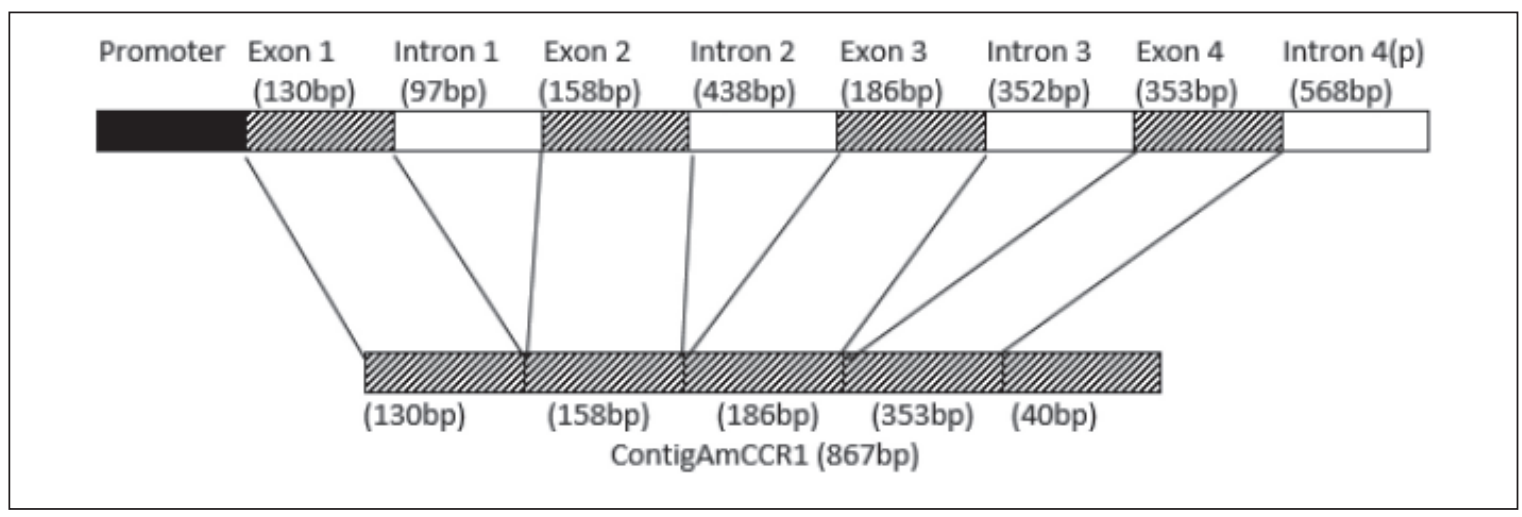

Fig. 1. The gene structure of $A m C C R 1$.

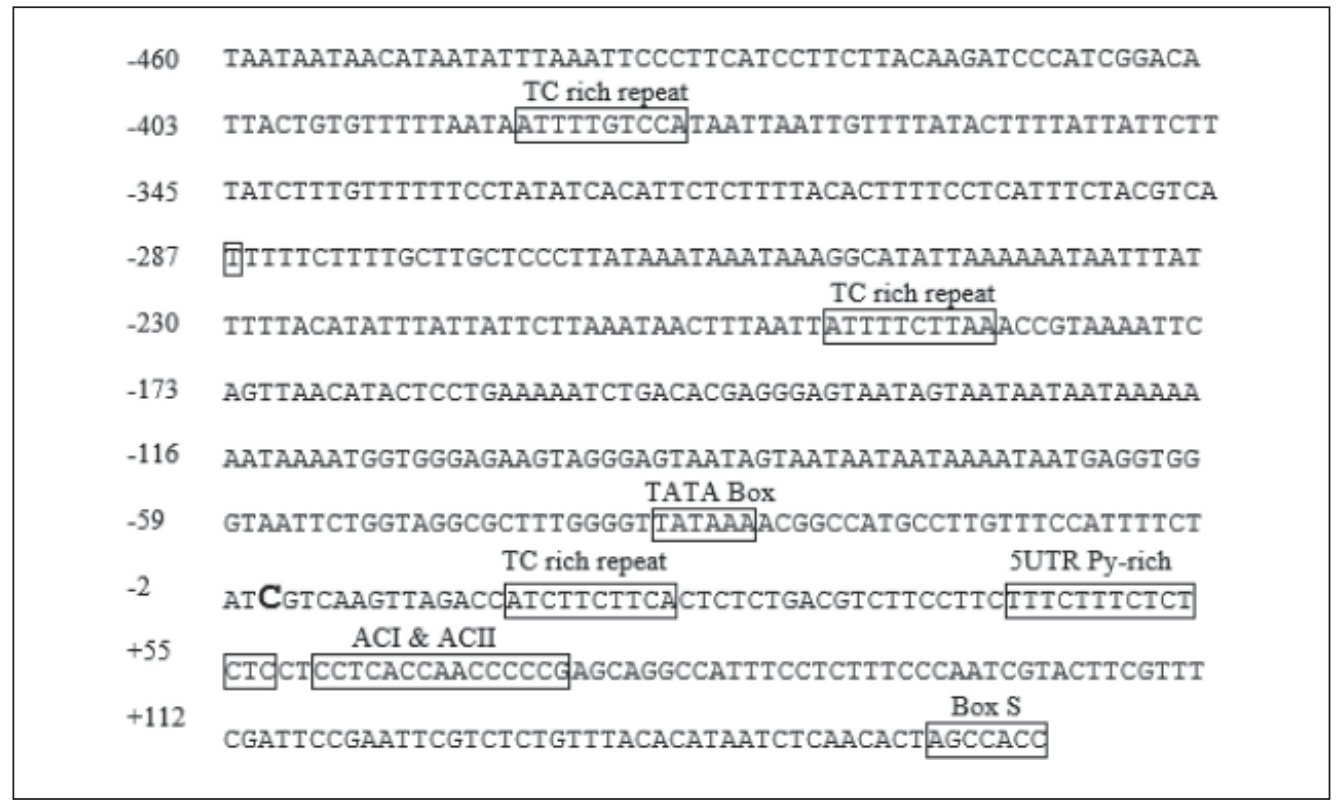

Fig. 2. Cis elements of $A m C C R 1$. Transcription Start Site marked in bold.

auriculiformis $\times$ Acacia mangium hybrid. Sequence analysis however, detected a nonsense mutation on the first exon. Thus, this gene is named pseudoCOMTAm (Genbank accession number: MF488717). The high sequence similarity is within $211 \mathrm{bp}$ in promoter region and extends to $110 \mathrm{bp}$ after the start codon (Figure 2).

Based on the sequence of the 400bp fragment, new primers were designed. GSP1, GSP2 and GSP3 were used in combination with $\mathrm{AD} 2$ to further amplify the 5' region while M1, M2 and AD2 were used to further amplify the 3' region. The total size of the promoter isolated is $770 \mathrm{bp}$. PLANTCARE analysis showed presence of multiple cis acting elements (Figure 3). Core promoter element, TATA Box was found at position -22. 5UTR Py-rich stretch, a cis-acting element which confers high transcription levels were identified at -261 . Cis acting elements commonly found in genes acting in lignin and phenylpropanoid pathway, ACI and ACII elements were identified at position -77 and -40 respectively. AC elements are known to interact with MYB transcription factors and function in coordinated regulation of lignin and phenylpropanoid biosynthetic pathway genes (Zhou et al., 2009).

W box which functions in defence against pathogen was found at -421 . Besides that, two motifs which regulate endospermic gene expression, GCN4 and Skn-1 were found at -619 and -43 . Abscisic acid responsiveness motif, $A B R E$ was found at -110 while ARE motif which functions in anaerobic induction were found at -496 . P-box, motif known to function in gibberellin response was found at +2 . Multiple cis elements which function in light responsiveness like ATCT-motif, Box I, GA-motif and GT1-motif were also identified in this promoter (Figure 4). This is not surprising as lignin genes are also known to be involved in crosstalk with other plant physiological process (Rogers et al., 2005). 


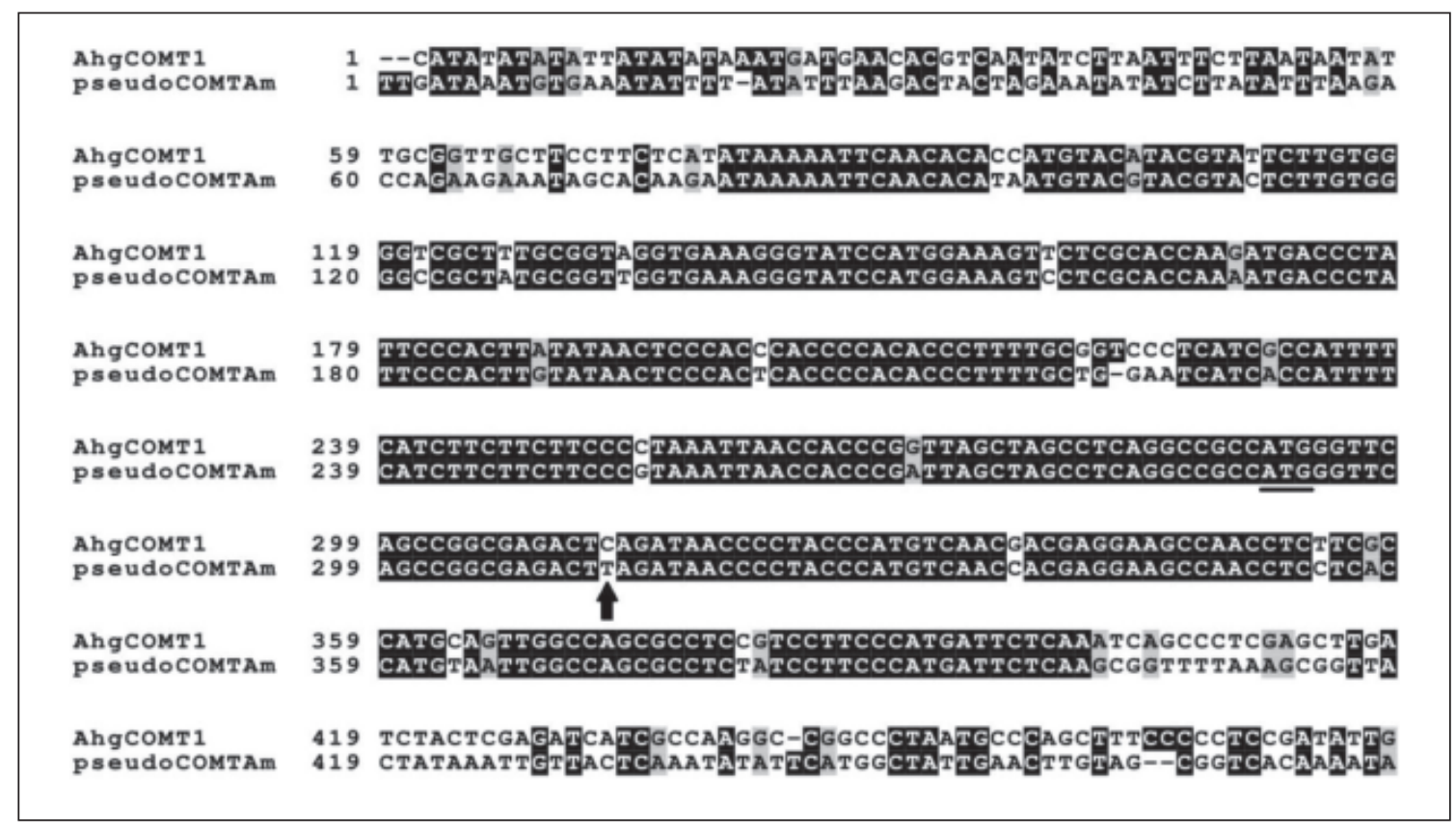

Fig. 3. Alignment of pseudoCOMTAm and AhgCOMT1. Start codon is underlined. Arrow shows mutation that creates premature stop codon.

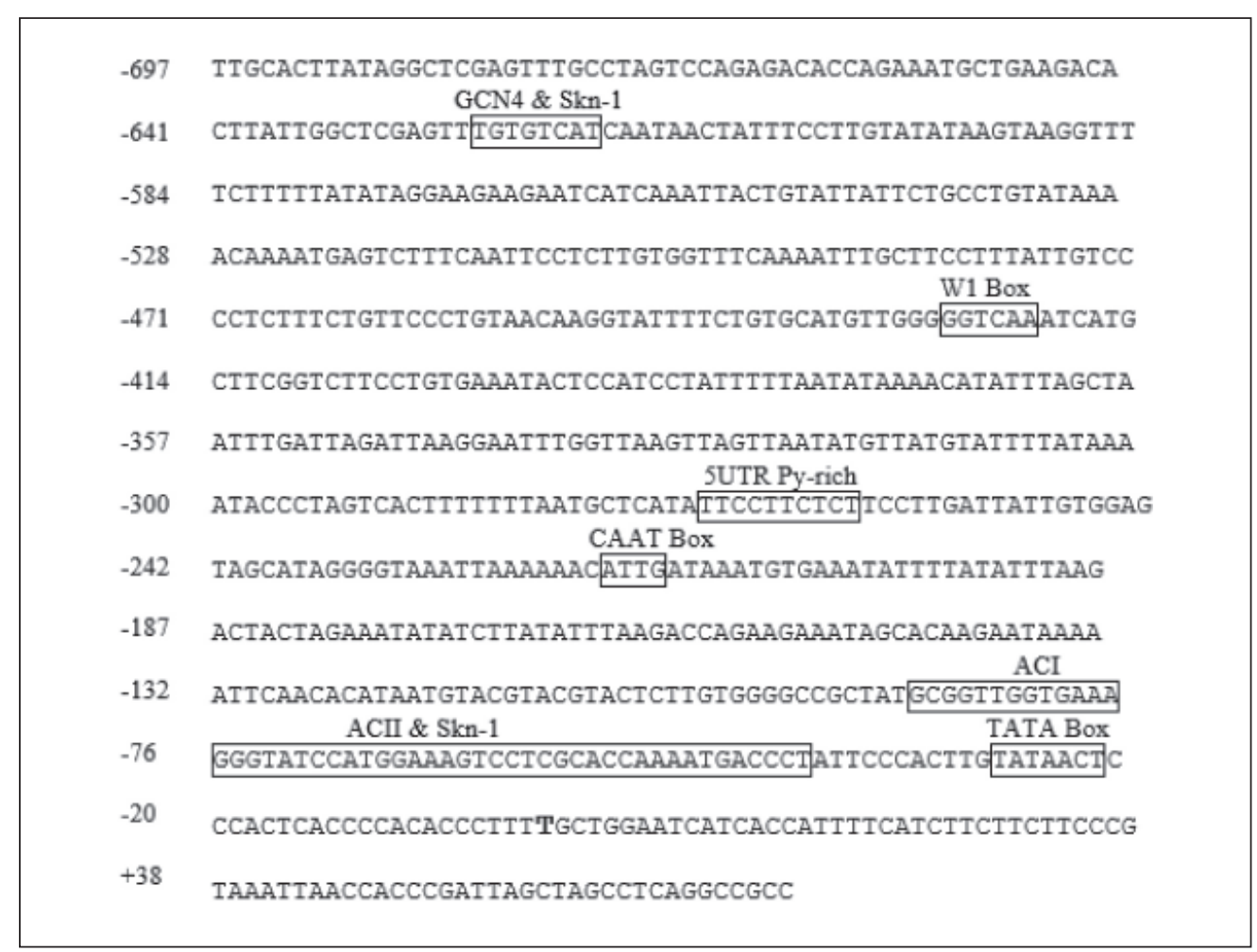

Fig. 4. cis elements of pseudoCOMTAm. Transcription Start Site marked in bold.

\section{ACKNOWLEDGEMENTS}

The authors would like to thank Faculty of Science and Technology, Universiti Kebangsaan Malaysia and School of Biosciences, Taylor's University for supporting this research.

\section{REFERENCES}

Altschul, S.F., Gish, W., Miller, W., Myers, E.W. \& Lipman, D.J. 1990. Basic local alignment search tool. Journal of Molecular Biology, 215(3): 403-410. 
Boerjan, W., Ralph, J. \& Baucher, M. 2003. Lignin biosynthesis. Annual Review of Plant Biology, 54: 519-546.

Boudet, A.M., Kajita, S., Grima-Pettenati, J. \& Goffner, D. 2003. Lignins and lignocellulosics: a better control of synthesis for new and improved uses. Trends in Plant Science, 8(12): 576-81.

Griffin, A.R., Midgley, S.J., Bush, D., Cunningham, P.J. \& Rinaudo, A.T. 2011. Global uses of Australian acacias - recent trends and future prospects. Diversity and Distributions, 17(5): 837-847.

Grima-Pettenati, J. \& Goffner, D. 1999. Lignin genetic engineering revisited. Plant Science, 145(2): 51-65.

Hall, T.A. 1999. BioEdit: a user-friendly biological sequence alignment editor and analysis program for Windows 95/98/NT. Nucleic Acids Symposium Series, 41: 95-98.

Lauvergeat, V., Lacomme, C., Lacombe, E., Lasserre, E., Roby, D. \& GrimaPettenati, J. 2001. Two cinnamoyl-CoA reductase (CCR) genes from Arabidopsis thaliana are differentially expressed during development and in response to infection with pathogenic bacteria. Phytochemistry, 57(7): 1187-1195.

Lescot, M., Déhais, P., Thijs, G., Marchal, K., Moreau, Y., Van de Peer, Y., Rouzé, P. \& Rombauts, S. 2002. PlantCARE, a database of plant cis-acting regulatory elements and a portal to tools for in silico analysis of promoter sequences. Nucleic Acids Research, 30(1): 325 327.

Liu, Y-G. \& Whittier, R.F. 1995. Thermal asymmetric interlaced PCR: automatable amplification and sequencing of insert end fragments from P1 and YAC clones for chromosome walking. Genomics, 25(3): 674-681.

Mazars, G.R., Moyret, C., Jeanteur, P. \& Theillet, C.G. 1991. Direct sequencing by thermal asymmetric PCR. Nucleic Acids Research, 19(17): 4783.

Ong, S.S. \& Wickneswari, R. 2011. Expression Profile of small RNAs in Acacia mangium Secondary Xylem Tissues with Contrasting Lignin Content - potential regulatory sequences in monolignol biosynthetic pathway. $B M C$ Genomics, 12: S13.

Prashant, S., Sunita, M.S.L., Sirisha, V.L., Bhaskar, V.V., Rao, A.M., Narasu, M.L. \& Kavi Kishor, P.B. 2012. Isolation of cinnamoyl CoA reductase and cinnamyl alcohol dehydrogenase gene promoters from Leucaena leucocephala, a leguminous tree species, and characterization of tissue-specific activity in transgenic tobacco. Plant Cell, Tissue and Organ Culture, 108(3): 421-436.
Raes, J., Rohde, A., Christensen, J., Van de Peer, Y. \& Boerjan, W. 2003. Genome wide characterization of the lignification toolbox in Arabidopsis. Plant Physiology, 133(3): 10511071.

Rogers, L.A., Dubos, C., Cullis, I.F., Surman, C., Poole, M., Willment, J., Mansfield, S.D. \& Campbell, M.M. 2005. Light, the circadian clock, and sugar perception in the control of lignin biosynthesis. Journal of Experimental Botany, 56(416): 1651-1663.

Shi, R., Sun, Y.H., Li, Q., Heber, S., Sederoff, R. \& Chiang, V.L. 2010. Towards a Systems Approach for lignin biosynthesis in Populus trichocarpa: Transcript Abundance and Specificity of the Monolignol Biosynthetic Genes. Plant and Cell Physiology, 51(1): 14463.

Sievers, F., Wilm, A., Dineen, D., Gibson, T.J., Karplus, K., Li, W., Lopez, R., McWilliam, H., Remmert, M., Söding, J., Thompson, J.D. \& Higginsa, D.G. 2011. Fast, scalable generation of high-quality protein multiple sequence alignments using Clustal Omega. Molecular Systems Biology, 7: 539.

Sukganah, A., Choong, C.Y., Russell, J., Neale, D. \& Wickneswari, R. 2013. Nucleotide sequence analysis of two lignin genes in Acacia auriculiformis $\times$ Acacia mangium hybrid for enhancement of wood pulp quality. Tree Genetics \& Genomes, 9(5): 1369-1381.

Thanh, T., Chi, V.T., Abdullah, M.P., Omar, H. \& Napis, S. 2012. Efficiency of ligation-mediated PCR and TAIL-PCR methods for isolation of $\mathrm{RbcS}$ promoter sequences from green microalgae Ankistrodesmus convolutus. Molecular Biology, 46(1): 64-70.

Whetten, R.W., MacKay, J.J. \& Sederoff, R.R. 1998. Recent advances in understanding lignin biosynthesis. Annual Review of Plant Physiology and Plant Molecular Biology, 49: 585-609.

Wong, M.M., Cannon, C.H. \& Wickneswari, R. 2011. Identification of lignin genes and regulatory sequences involved in secondary cell wall formation in Acacia auriculiformis and Acacia mangium via de novo transcriptome sequencing. BMC Genomics, 12: 342.

Zhao, Q. \& Dixon, R.A. 2011. Transcriptional networks for lignin biosynthesis: more complex than we thought? Trends in Plant Science 16(4): 227-233.

Zhou, J., Lee, C., Zhong, R. \& Ye, Z.H. 2009. MYB58 and MYB63 are transcriptional activators of the lignin biosynthetic pathway during secondary cell wall formation in Arabidopsis. Plant Cell, 21(1): 248-266. 